\title{
AS APROPRIAÇÕES CULTURAIS DA RAINHA CLEÓPATRA VII NA CONTEMPORANEIDADE: UM ESTUDO A PARTIR DO FILME CLEÓPATRA, DE 1963
}

\section{CULTURAL APPROPRIATIONS OF THE QUEEN CLEOPAT- RA VII IN CONTEMPORANEITY: A STUDY FROM THE MOV- IE CLEOPATRA, 1963}

Bárbara Oliveira ${ }^{1}$

Resumo: O presente artigo visa abranger alguns aspectos do estudo de gênero, inseridos dentro do campo historiográfico da história cultural, abordando o tema da egiptomania e da história do cinema, relacionando os aspectos referentes às produções cinematográficas que remetam a Rainha egípcia Cleópatra VII. Pretende-se trabalhar também com a inserção das mulheres no cinema, a partir do filme Cleópatra, de Joseph Mankiewicz, tratando questões como erotismo e sexualidade da personagem de Elizabeth Taylor.

Palavras-chave: Egiptomania; Cinema; Cleópatra VII; Usos do Passado; Elizabeth Taylor; Erotismo

Abstract: This paper aims to discuss gender studies and cultural history, considering Egyptomania and the image of Egyptian Queen Cleopatra VII on moves. I shall focus at the inclusion of women in cinema and discuss eroticism and sexuality of Elizabeth Taylor's character on Cleopatra, by Joseph Mankiewicz.

Keywords: Egyptomania; Cinema; Cleopatra VII; Uses of the Past; Elizabeth Taylor; eroticism

\footnotetext{
${ }^{1}$ Graduanda em História - Bacharelado com Licenciatura pela Universidade Federal do Paraná. Bolsista PIBIC/CNPq, sob orientação da Prof. Dra. Renata Senna Garraffoni. E-mail: bahzinha91@gmail.com. Lattes: http://lattes.cnpq.br/9673914231653139.
} 


\section{Introdução}

Temas relativos ao Antigo Egito quase sempre provocam encanto e fascínio nas pessoas, sobretudo fora do ambiente acadêmico. Estes sentimentos remontam à Antiguidade: quase um milênio atrás, os antigos egípcios já fascinavam Heródoto, Plutarco e Estrabão, por exemplo. Os escritos destes autores resistiram ao tempo e se tornaram referência para o estudo da sociedade egípcia, junto com a cultura material, por meio da arqueologia e da epigrafia. Embora as fontes para se trabalhar a antiguidade egípcia sejam abundantes, o tema é pouco explorado dentro do ambiente acadêmico, no Brasil. Isso se deve, em partes, ao fato de que as bibliografias que trabalham questões relativas ao Egito serem, em sua maioria, em outros idiomas, como francês, inglês e árabe. Quando, portanto, um historiador brasileiro volta sua pesquisa para temas relacionados ao Egito Antigo, ele assume, academicamente, um desafio. E ao se voltar, especificamente, para a rainha Cleópatra VII, pode-se dizer que o desafio do historiador aumenta, no sentido em que além de se tratar de um contexto pouco explorado no Brasil - a antiguidade egípcia -, estudar a rainha Cleópatra VI compreende debruçar-se sobre os estudos de gênero, os quais há pouco tempo começaram a se desenvolver na egiptologia.

Rainha ptolomaica, Cleópatra VII, governou o Egito de 51 a 30 a.C. No entanto, pouco se sabe sobre seu governo ou mesmo sua vida. $\mathrm{O}$ que é conhecido sobre a rainha, deriva de escritos de posteriores, sendo, sem dúvida, os mais famosos os escritos de Plutarco em "Vidas de Césares", "Vidas Paralelas" e "Vidas de Antonio". Historiador grego que 
nasceu, aproximadamente, 15 anos depois da morte da rainha, e que dedicou sua vida a escrever as histórias de romanos ilustres na Antiguidade, Plutarco chegou à história de Cleópatra por meio de - sobretudo de relatos orais, destacando os relatos de Olímpio, médico e tutor da rainha (SCHWENTZEL, 2009, p. 18). Levando em consideração estes textos como fontes históricas, fica evidente a dificuldade de se observar um personagem feminino sob o olhar masculino que os escreveu. Esta é uma das maiores dificuldades do campo historiográfico ao se estudar a mulher da Antiguidade: a perspectiva é, quase sempre, masculina. Neste sentido, as produções historiográficas que abordem o universo tangente à rainha Cleópatra VII são poucas e, quase sempre, trazem as mesmas perspectivas das escassas fontes sobre o assunto.

Contudo, fora do ambiente acadêmico, é quase impossível mencionar o nome da rainha egípcia, atualmente, sem se deparar com opiniões sobre sua história, legado ou mesmo sua aparência. Estas reações são em sua maioria - reflexos das obras de Plutarco, que se popularizaram no Ocidente, ao longo dos séculos, com as releituras para o teatro e literatura, como 'Marco Antonio e Cleópatra', de Shakespeare, sem contar as inúmeras representações imagéticas que foram feitas da rainha, principalmente no período renascentista e iluminista, com autores como Alexandre Cabanel. Além disso, existem diversas produções audiovisuais acerca de Cleópatra, relacionadas à televisão e ao cinema, por exemplo.

Pretende-se, neste artigo, fazer um estudo a partir destas apropriações culturais e releituras da imagem de Cleópatra VII. Para tanto, inici- 
almente abordaremos algumas questões relativas aos estudos de gênero e à egiptomania, que compreendem boa parte do referencial teórico sobre o tema. A partir dos estudos de egiptomania, nos deteremos, com especial atenção, às imagens da rainha egípcia no meio cinematográfico e, portanto, em seguida abordaremos a temática das mulheres no cinema, para, enfim chegarmos à análise da imagem de Cleópatra VII no cinema. Pretende-se, a partir deste artigo, compreender as imagens criadas e reproduzidas da rainha Cleópatra VII a partir de uma breve análise fílmica de Cleópatra, de 1963.

\section{Entre o Gênero e a Egiptomania: O Egito e as Mulheres}

O estudo sobre a mulher na historiografia mundial é, de certo modo, muito recente, e surge, de forma relevante, após as revoluções dos Annales, onde diversos autores passaram a difundir as questões historiográficas relevantes a sociedade marginal e excluída. No livro $A$ História Nova, de Jacques Le Goff, há um texto de Jean-Claude Schmitt, onde o autor explica a usual exclusão de temas marginais na história elitista, que centralizava a sociedade dominante de poder e excluía aqueles que, segundo esta historiografia, não seriam relevantes aos episódios que de fato "fariam" a história. Contudo, Schmitt propõe ao historiador uma visão diferente desta, usual nas academias até então, incentivando um olhar para esta 'nova história', que ouviria todas as vozes da sociedade, e não mais somente a voz vigente de poder. Eis que aqui surgem novas pesquisas que abordam o gênero, agora como parte desta nova história. Neste sentido, é interessante salientar os estudos da histo- 
riadora Michelle Perrot sobre as mulheres em suas obras Mulheres ou os silêncios da história, Os excluídos da história: operários, mulheres e prisioneiros e sua famosa parceria com Georges Duby, História das mulheres do ocidente. Estes estudos de Perrot modificaram, de certo modo, o estudo da mulher na historiografia - que até então se restringia às personagens "célebres" da História - e passaram a estudar a mulher, em seu todo, não mais vista pelo olhar da sociedade predominantemente masculina que a cerca.

A partir da historiografia voltada para a antiguidade, temos a obra Amor, desejo e poder na Antiguidade - Relações de gênero e representações do feminino, organizada pelos historiadores Pedro Paulo Abreu Funari, Lourdes Conde Feitosa e Glaydson José Silva. No livro, Pedro Paulo Abreu Funari nos explica que há uma longa tradição de exclusão historiográfica, no sentido de que, os discursos que são comumente estudados e chegam até nós, não abrangem todos os antigos, embora, em sua teoria, sejam discursos homogêneos (P. FUNARI, 2003, p.24). No que se refere a essa construção historiográfica, segundo Funari, as "pessoas comuns" a qual a historiografia se refere, na verdade se refere a uma elite masculina, que exclui majoritariamente as mulheres. Neste sentido, pesquisas relacionadas aos estudos de gênero na antiguidade justificam-se ao buscar trazer a heterogeneidade da historiografia referente à antiguidade, sobretudo no que se tange a mulher antiga.

A partir disso, propõe-se, neste artigo, analisar e discutir a imagem da rainha egípcia Cleópatra VII, produzida a partir de apropriações culturais de sua história. A estas releituras e apropriações culturais da 
antiguidade egípcia na contemporaneidade dá-se o nome de egiptomania. Pesquisadores como Margareth Bakos ${ }^{2}$ e Raquel dos Santos Funari ${ }^{3}$, no Brasil, tratam do tema da egiptomania em seus diversos aspectos da sociedade. No campo relacionado às produções audiovisuais, e especialmente ao cinema, as pesquisas de Funari têm relevante importância, analisando não só as apropriações históricas que o cinema fez/faz da cultura do Antigo Egito, bem como os reflexos que estas apropriações trazem para a sociedade atual. Assim, para Funari a linguagem cinematográfica transmite recursos estratégicos fundamentais para a construção da identidade cultural da sociedade interpretada, bem como da sociedade que a interpreta (FUNARI, 2012, p.30). Também na vertente cinematográfica, aliado a questão dos usos do passado, nos apoiamos fortemente na obra Projecting the past - Ancient Rome and History, da autora Maria Wyke ${ }^{4}$, que aborda a questão do cinema épico e a importância dos temas históricos inseridos no cinema. Maria Wyke, em suas pesquisas

\footnotetext{
${ }^{2}$ Líder de grupo de pesquisa que trabalha com as questões relativas à egiptomania no Brasil. http://plsql1.cnpq.br/buscaoperacional/detalhegrupo.jsp?grupo=0006705CJCR YUW

${ }^{3}$ Doutora em História, têm pesquisas relevantes na área de egiptomania, atuando em grupos de pesquisa cadastrados no $\mathrm{CNPq}$, como História da Egiptomania no Brasil;, liderado pela Profa. Dra. Margaret Bakos (PUCRS), assim como em grupos sediados na UNIFESP (Antiguidade e Modernidade: História Antiga e usos do Passado) e na UNICAMP. Recentemente publicou FUNARI, Raquel Santos. "O Príncipe do Egito", um filme e suas leituras na sala de aula. Primeira edição. São Paulo: Annablume/Unicamp, 2012. V. 1. 190 p.

${ }^{4}$ Maria Wyke é uma historiadora inglesa, especialista em antiguidade. Trabalha principalmente com estudos clássicos e tem alguns trabalhos publicados acerca das representações dos estudos clássicos na contemporaneidade.
} 
relacionadas ao cinema, propõe uma forma de interação nova entre o historiador e o filme. Para Wyke, os pesquisadores de História Antiga tem um preconceito para com o cinema, levando em consideração que este é um meio de comunicação contemporâneo e, neste sentido, não teria relação com os estudos de antiguidade. Contudo, a autora nos demonstra que o cinema pode ter grande utilidade nas pesquisas relacionadas à antiguidade, principalmente naquelas relacionadas aos usos do passado.

Ao nos debruçarmos nos estudos relacionados à rainha Cleópatra VII, é importante termos em mente que "a lenda de Cleópatra sofreu muitas metamorfoses nos dois milênios que sucederam a sua morte" (HUGHES-HALLETT, 2005, p.14). Ao longo dos dois mil anos que se passaram desde a morte de Cleópatra, sua história foi recontada tantas vezes, em tantos lugares e por tantas pessoas diferentes, que acabou por se transformar. O que a historiadora Lucy Hughes-Hallett ${ }^{5}$ quer dizer é que os relatos plutarquianos foram moldados de acordo com as convenções e padrões sociais vigentes na época em que as histórias eram narradas. Ao analisarmos o filme de 1963, nós sabemos não estar nos deparando com uma reprodução da verdade histórica de Cleópatra - assim como isso não ocorreria ao debruçarmo-nos sobre as fontes escritas por Plutarco, ainda na antiguidade. Gregory Balthazar ${ }^{6}$ também trabalha com a ambiguidade existente na figura de Cleópatra que, para ele, é

\footnotetext{
${ }^{5}$ Historiadora, crítica literária e jornalista. Trabalha principalmente com biografias de personagens históricos.

${ }^{6}$ Mestre em História Antiga pela Universidade Federal do Paraná. Seus objetos de estudo relacionam-se com Egito Antigo, Plutarco e a rainha Cleópatra VII.
} 
proveniente dos próprios relatos plutarquianos, no sentido de que Plutarco, ao coletar informações, buscou conhecer a versão dos partidários de Otávio, bem como de pessoas favoráveis à rainha. Assim, essa imagem ambígua, segundo Balthazar, foi responsável por cativar o público ao longo dos séculos, ao se criar uma rainha egípcia, com fortes apelações eróticas e sexuais, mas também políticas e maternais. Em sua dissertação de mestrado, Balthazar nos afirma que a Cleópatra vista em nossa contemporaneidade é fruto de reinterpretações e releituras de sua história, ao longo dos séculos (BALTHAZAR, 2013, p.18). De certa forma é possível afirmar que sua história foi recontada tantas vezes, em tantos lugares e por tantas pessoas diferentes, que acabou por se transformar. O que Hughes-Hallett e Balthazar querem dizer é que os relatos plutarquianos foram moldados de acordo com as convenções e padrões sociais vigentes na época em que as histórias eram narradas. Sobre a questão da verdade histórica de Cleópatra, Gregory Balthazar, ainda em sua dissertação de mestrado, trabalha com as contradições feitas pelos historiadores nesta eterna busca pela "verdadeira Cleópatra". Para o autor, o discurso reproduzido por autores clássicos, como Plutarco e Dion Cassio, são reflexos da versão de rainha egípcia propagandeada pelo imperador romano Otávio Augusto (BALTHAZAR, p.54). Da mesma forma, Hugues-Hallet explica que, embora os escritores clássicos que remeteram a Cleópatra tivessem autonomia de escrita, todos eles deveriam, de alguma forma, fidelidade a Roma (HUGHESHALLETT, p.67). 


\section{A representação das mulheres no cinema}

Ao trabalharmos com uma documentação que aborda essencialmente uma figura feminina, temos que ter o cuidado de compreender os olhares masculinos sobre ela impostos. A antiguidade na historiografia é, seguindo esta premissa, um produto do olhar masculino e ao chegar ao cinema, portanto, carrega consigo este olhar. Compreendemos, desta forma, que "o cinema, como todos os demais produtos culturais de nossa sociedade de matriz patriarcal, tiveram e têm a marca dos homens, da visão masculina do mundo" (TONETO, 2011, p.8). Ao trabalharmos com um filme que aborda a antiguidade e um personagem feminino ao mesmo tempo, temos que compreender, principalmente, as imposições masculinas em sua narrativa e na construção de sua personagem. Além disso, é importante ressaltar que o cinema com temáticas relativas à Antiguidade apresenta características de usos do passado, isto é, faz apropriações de sua contemporaneidade na trama da história.

No caso dos filmes relacionados às mulheres também se mantém essa relação de imposição masculina na construção dos personagens. Portanto, ao nos depararmos com uma personagem feminina no cinema, a analisamos, sobretudo, a partir da pesquisa da historiadora feminista Elizabeth Ann Kaplan, que trabalha, desde a década de 1970, com as mulheres e o cinema - seja nas representações femininas nos filmes, como nas mulheres diretoras e atrizes. Ann Kaplan é referência mundial em pesquisas relacionadas aos estudos de gênero e cinema por ser uma das fundadoras do conceito de abordagem feminista nas críticas cinematográficas. Junto com outras pesquisadoras, como Laura Mulvey e Mary 
Ann Donn, criou uma nova perspectiva para avaliar o cinema clássico narrativo das décadas de 1940 e 1950, principalmente, e refletir acerca do papel das mulheres nestes filmes. Em seu livro, A mulher e o cinemaos dois lados da câmera, Kaplan apresenta uma teoria de que está presente, a produção cinematográfica clássica hollywoodiana, o domínio do olhar masculino e, neste sentido, é quase sempre moldado para ter representações femininas eróticas e explicitamente sexuais (KAPLAN, 1995, p.23). Segundo Ann Kaplan, os papeis femininos no cinema são justificados, entre outros aspectos, por Freud e os conceitos de voyeurismo e fetichismo, no sentido de que os mecanismos utilizados para representar a mulher cinematograficamente estão relacionados com as construções inconscientes do espectador, em sua maioria, masculino. Para a autora, o cinema hollywoodiano, geralmente, constrói personagens baseados no patriarcalismo tradicional e, neste sentido, a imagem das mulheres nas telas são sexualizadas, independente do que estas mulheres estejam fazendo ou em quais enredos elas estejam envolvidas (KAPLAN, p.53). Uma questão levantada pela autora é a relação da sexualidade feminina e o cinema. Para Kaplan, as abordagens das mulheres cinematográficas estão intrínsecas a uma resistência da cultura patriarcal, nas quais as mulheres são privadas de sua liberdade sexual e, quase sempre, são super sexualizadas pelas câmeras.

No Brasil, as pesquisas relacionadas às mulheres e ao cinema veem crescendo muito nos últimos anos. Uma das pesquisadoras de maior destaque neste tema atualmente é a historiadora e jornalista Maria Cristina Tonneto, que trabalha com as relações entre o Cinema e a História, 
bem como a representação do feminino no cinema a partir de diversos vieses, como a compreensão histórico-social dos contextos fílmicos e as ideologias adotadas para as representações femininas cinematográficas. Para a historiadora, foi o star system ${ }^{7}$ que ampliou o papel das mulheres nas telas de cinema (TONETTO, p.13). Os primeiros surgimentos deste novo perfil de atriz - que tinha voz, embora, muitas vezes estas vozes fossem dos roteiristas e diretores - foram associados, principalmente, a necessidade do surgimento de divas para a Sétima Arte.

Estas atrizes modificaram a representação na narrativa cinematográfica. Até a década de 40, a maioria dos papéis femininos se resumia à mocinha virginal, à dona de casa, à mãe dedicada, à esposa encantadora. Representações que não fugiam do olhar da sociedade sobre o sexo feminino, ou seja, mulheres sem sexualidade, sem espaço nas frentes de trabalho, na política e demais campos destinados ao sexo masculino (TONETTO, p.22).

Contudo, a partir da década de 1940 - e mais precisamente, a partir da década de 1950, com o surgimento e expansão da televisão - o meio cinematográfico tem a necessidade de buscar novas formas de atingir o público. É neste momento que, para Tonneto, abre-se espaço para a mulher desinibida, com sex-appeal e aparência provocante (TONETTO, p.23). A autora nos explica que "o erotismo foi a fórmula en-

${ }^{7}$ Conceito utilizado por diversos pesquisadores de Cinema que refere-se, sobretudo, ao período entre as décadas de 1920 e 1960, em Hollywood, nas quais as produtoras de cinema dar ênfase as imagens dos atores, glamurizando não somente os personagens, mas também os atores que os interpretavam. Para saber mais, Basinger, Jeanine (2007). The Star Machine. NY: Alfred A. Knopf. p. 18. 
contrada pelos diretores para colocar no écran as mulheres sem o apelo virginal" (TONETTO, p.23).

Esta erotização da mulher está relacionada, sobretudo, com a necessidade da indústria cinematográfica para conquistar o público e os manter fiel por meio da imagem, da fantasia e dos personagens, conforme nos explica Ann Kaplan. A autora afirma que o cinema contemporâneo, após a década de 1960, apresenta uma representação explicita da sexualidade feminina, embora conflite constantemente entre os padrões estabelecidos pela sociedade patriarcal e os movimentos de liberação feminina que encorajaram as mulheres a tomarem posse de sua própria sexualidade (KAPLAN, p.23). Em Hollywood, no entanto, segundo Kaplan, é a "ideia expressa de que todas as mulheres anseiam o tempo todo pelo sexo oposto" (KAPLAN, p.23) que mantém o normativismo patriarcal exposto no meio cinematográfico. Isto é, partindo de um pressuposto de que toda mulher é extremamente sexualizada e anseia pela dominação masculina, a indústria cinematográfica se utiliza deste tipo de argumentação para veicular seus filmes. Neste contexto, compreende-se que existe no cinema uma necessidade de utilizar o falo como principal arma para a dominação feminina em seus enredos.

\section{A rainha egípcia no cinema}

Ao trabalharmos com o cinema, uma questão importante é acerca da construção dos personagens. No entanto, tratando-se de personagens históricos, torna-se fundamental compreender as relações entre o personagem histórico criado e aquele que, de fato, existiu. No caso da rainha egípcia Cleópatra VII, é necessário lembrarmos que todos os relatos 
sobre ela que chegaram até nós, derivam de escritos clássicos, em sua maioria provenientes de não egípcios que tinham interesses políticos divergentes do Egito, conforme já comentamos. Ao lermos as obras de Plutarco, Suetonio e Dion Cássio, nos deparemos com suas impressões acerca da rainha egípcia, bem como com as impressões que eles gostariam de passar a seus contemporâneos. Neste sentido, temos que ter certa cautela ao analisar os aspectos derivados destes relatos. Contudo, por se tratarem das principais documentações escritas disponíveis sobre Cleópatra, são por meio delas que as personagens cinematográficas da rainha egípcia foram construídas e chegaram até nós.

A história de Cleópatra tem sido contada e recontada há mais de dois mil anos, o que, provavelmente, cria uma distinção entre a verdade atestada e as lendas e distorções provocadas pelo tempo. Para a pesquisadora Lucy Hughes-Hallett, em seu livro Cleópatra, histórias, sonhos e distorções, "mesmo durante o período em que viveu ela foi, e várias vezes, reinventada" (HUGHES-HALLETT, p.31). Isso porque a história de Cleópatra se mistura nas histórias do Egito e de Roma. Sally-Ann Ashton, em seu livro Cleopatra and Egypt, explica que "não é fácil retirar a rainha Cleópatra do contexto histórico romano"8 (ASHTON, p.15). Desta forma, ao nos debruçarmos sobre a Cleópatra de Elizabeth Taylor, no filme de 1963, estamos analisando uma personagem criada a partir de outras personagens e, não necessariamente, conhecendo as possibilidades de uma Cleópatra "real". Devemos ter em mente, sobretudo, que:

\footnotetext{
${ }^{8}$ No original: "It is not easy to extract Cleopatra from a Roman historical context". Todas as traduções são de responsabilidade da autora.
} 
Cada imagem de Cleópatra (como peças de cerâmica do arqueólogo) fornece pistas sobre a natureza da cultura que a produziu, particularmente em relação a suas concepções sobre sexo, os seus preconceitos raciais, suas neuroses e suas fantasias (HUGHESHALLET, p.15)

Assim, o cinema nos apresenta uma imagem da rainha egípcia criada por nossa contemporaneidade e, no caso do Cleópatra de Mankiewicz, uma imagem específica acerca da sociedade estadunidense da década de 1960. Neste sentido, Lucy Hughes-Hallett nos explica que:

Cleópatras (como Satãs, como Cristos, como as imagens de qualquer personagem frequentemente representado por longos períodos de tempo) são sempre recriadas pelos indivíduos que as imaginam e pelas sociedades em que essas pessoas vivem (HUGHES-HALLETT, p.15).

Compreendemos, a partir dos trabalhos de Raquel dos Santos Funari, que a construção da personagem de Cleópatra no cinema é parte da jornada do herói, baseado na obra O herói de mil faces, de Joseph Campbell, o qual foi apropriado pelo cinema a partir das adaptações para roteiristas por Christopher Vogler. A proposta de Campbell é a de que uma narrativa sem um personagem heroico não se desenrola: o herói é necessário para a aventura e para o enredo da narrativa. Neste sentido, a autora Raquel Funari nos explica que:

Um dos poderes mágicos do filme deve ser sua capacidade de seduzir cada membro da plateia para que cada um projete uma parte de seu ego no personagem que está na tela. A identificação de- 
riva do fato de o herói ter objetivos, impulsos, desejos e necessidades universais (FUNARI, p.46).

Primeiramente, devemos compreender que a sedução da qual Funari se refere é no sentido de atração do público pelo personagem e não em seus aspectos eróticos e sexuais. A partir deste ponto, portanto, compreendemos que a sedução necessária ao herói para a construção de seu personagem e narrativa deve estar relacionada aos aspectos psicológicos dos espectadores.

Desta forma, a questão da sedução no contexto cinematográfico é fundamental, no sentido de que o público espectador precisa de um ponto de identificação com o filme para que se prenda a trama. Conforme já explicamos nos itens anteriores, alguns aspectos desta sedução cinematográfica estão relacionados com a emoção e o desenvolvimento psicológico da trama do filme, ou seja, o personagem principal desenvolve um problema com o qual o público se identifica ou se projeta nele, criando um relacionamento entre o personagem e o espectador. Para o pesquisador Luiz Vadico, a construção de personagens históricos no cinema está relacionada, principalmente, com a "análise psicológica" do personagem, isto é, a conveniência de se retratar um personagem que se encaixe nas tendências psicológicas contemporâneas ao filme (VADICO, 2008, p.139). Para Vadico, a análise psicológica dos personagens cinematográficos se relaciona, também, com o contexto histórico-social de produção do filme. Neste sentido, a sedução do personagem principal se relacionará com as necessidades do público contemporâneo a ele e, para Vadico, podem se alterar de acordo com a época que o filme for 
assistido - ou seja, um filme produzido no contexto da Guerra do Vietnã, por exemplo, tem em seu personagem principal um significado diferente para nós do que aquele esperado/atingido na época de produção e lançamento do filme, isto porque nós reconhecemos o contexto histórico e podemos compreender a análise psicológica do personagem de uma perspectiva isolada da situação.

No caso do filme que nós analisamos aqui, no entanto, podemos considerar que parte da sedução da personagem Cleópatra de Elizabeth Taylor se encontra, provavelmente, na erotização da personagem, que está relacionada com a necessidade de os filmes hollywoodianos, no geral, servirem para reforçar padrões sociais normativos, bem como a objetificação do corpo feminino, constatando-se que o cinema continua sendo, predominantemente, uma forma de arte masculina. Se, por outro lado, nos detivermos a análise do contexto histórico-social para a construção da personagem de Cleópatra, nos depararemos com questões como a Guerra Fria, a imposição de uma suposta soberania dos EUA, as ondas feministas e até as relações do vanity fair entre o presidente Kennedy e a super star Marilyn Monroe. Ou seja, não podemos compreender exclusivamente o contexto histórico-social de produção do filme para a construção dos personagens, como tão pouco somente as tradições cinematográficas ou as análises psicológicas dos personagens e do público. Contudo, se analisarmos todos os aspectos de forma conjunta, poderemos finalmente entender o processo de criação dos personagens históricos no cinema. 


\section{Considerações Finais}

A partir destas análises relativas ao papel da mulher, da Antiguidade e da História no cinema, pudemos situar nossa documentação e compreender que o cinema não apresenta interpretações únicas e sim uma pluralidade de significados e interpretações.

A questão do erotismo e da sexualidade no filme de 1963 é, neste ponto de vista, agente construtor da identidade feminina de Cleópatra. Por ser derivado dos escritos de Shakespeare, por exemplo, o filme apresenta diversas conotações relacionadas à sua obra. Para Lucy Hughes-Hallet, em seu livro Cleópatra, histórias, sonhos e distorções, a característica essencial de Cleópatra na obra de Shakespeare é a de amante (HUGHES-HALLETT, p.194), fato que se repete no filme. A literatura e o cinema, frutos dos reflexos plutarquianos, apresentam diversas influências negativas derivadas dos romanos em relação à rainha egípcia. Neste sentido, o caráter erótico e sexual de Cleópatra são nada mais que demonstrações destes reflexos. Hughes-Hallet explica que em Roma, as privações físicas eram consideradas provas de virtuosidade, enquanto que no Egito, os padrões morais e a razão são esquecidos - o erotismo de Cleópatra era inimigo da razão romana (HUGHESHALLET, p.201). Contudo, a questão sexual e erótica relacionada à rainha egípcia é anterior as suas releituras e reinterpretações. Segundo Hughes-Hallet, o caráter sexual de Cleópatra surgiu ainda enquanto a rainha estava viva, a partir das propagandas negativas de Otávio (ainda não imperador Augusto), em suas campanhas pela ascensão ao poder. Otávio construiu um discurso no qual a rainha egípcia era exótica, eróti- 
ca e extremamente sexual, representando tudo aquilo que um homem romano, que desejasse a grandeza verdadeira, deveria rejeitar (HUGHES-HALLETT, p. 100). Com este discurso impactante, Otávio criou uma personagem de Cleópatra fascinante demais para ser esquecida. Para Hugues-Hallet, essa Cleópatra libertina, complementada por suas belezas, inspirou devaneios de muitos autores ao longo dos séculos (HUGHES-HALLET, p. 106). Aos poucos, o caráter predador da regina meretrix de Otávio cedeu lugar à rainha egípcia sedutora, femme fatale, ícone de fantasias sexuais. Desta forma, vemos no filme a construção de uma Cleópatra na qual o erotismo sobrepõe-se em relação às virtudes, a sexualidade sobrepõe-se em relação à razão e a personagem feminina do filme é construída de acordo com o olhar masculino que a representa. Para Diana Kleiner, em seu livro Cleopatra and Rome, esta Cleópatra cinematográfica é resultado de uma glamourização da rainha por meio de Plutarco e Otávio Augusto (KLEINER, 2005, p.05), no sentido de que a "Cleópatra-Elizabeth Taylor" do filme de Mankiewicz nada mais é do que a produção de uma narrativa da modernidade e, por este motivo, apresenta características condizentes com esta modernidade, tais como os valores da sociedade vigente. A identidade feminina que a Cleópatra de Elizabeth Taylor nos apresenta está intimamente relacionada com a mulher que viveu naquele período, no momento de produção do filme, naquela sociedade na qual o filme foi produzido. São estes reflexos que moldam a forma como a rainha egípcia é interpretada e reinterpretada em nossa contemporaneidade. 
Deste modo, podemos concluir que a Cleópatra na qual nos debruçamos não é aquela que viveu no século I a.C., nem tampouco a encontraremos nos relatos dos autores clássicos mencionados, como Plutarco, Dion Cassio ou Suetônio, no sentido de que mesmo em vida, a imagem da rainha egípcia já era moldada de acordo com propagandas políticas, seja dela mesma, no Egito ou de Otávio, em Roma. O que nos fica claro, portanto, é que é impossível encontrar um discurso completamente imparcial sobre o assunto e que o filme, a nosso ver, é um reflexo desta parcialidade, no sentido de transmitir os discursos dos escritos clássicos, bem como releituras e reinterpretações produzidas em nossa contemporaneidade. A(s) Cleópatra(s) contemporânea, conclui-se, carrega consigo a identidade daquele que a narra e do contexto em que se é narrado.

\section{Fonte}

Filme e roteiro de "Cleópatra”. Direção de Joseph L. Mankiewicz. Roteiro de Sidney Buchman, Ranald MacDougall e Joseph L. Mankiewicz. Produção pela 20th Century Fox. Estados Unidos. 243 minutos. Baseado nos livros "Vida e época de Cleópatra" (em inglês "The Life and Times de Cleópatra"), de Carlo Maria Franzero e "Antonio e Cleópatra", de Willian Shakespeare. 1963.

\section{Bibliografia}

ASHTON, Sally-Ann. Cleopatra and Egypt. Estados Unidos: Blackwell Publishing, 2008. 
BALTHAZAR, Gregory da Silva. Cleópatra, Poder e Sedução: A Imagem Através do Tempo. Porto Alegre: FFCH/PUCRS, 2009. (Monografia de Bacharelado).

- A(s) Cleópatra(s) de Plutarco: As múltiplas faces da última monarca do Antigo Egito nas Vidas Paralelas. Dissertação de mestrado. Curitiba: UFPR, 2013.

FERRO, Marc. Cinema e História. São Paulo: Paz e Terra, 2010.

FUNARI, Pedro Paulo; FEITOSA, Lourdes Conde; SILVA, Glaydson. Amor, Desejo e Poder na Antiguidade: Relações de Gênero e Representações do Feminino. Campinas: Editora da UNICAMP, 2003.

FUNARI, Raquel S. "O Príncipe do Egito", um filme e suas leituras na sala de aula. Primeira edição. São Paulo: Annablume/Unicamp, 2012. v. $1.190 \mathrm{p}$.

HUGHES-HALlETT. Lucy. Cleópatra: História, Sonhos e Distorções. Rio de Janeiro: Record, 2005.

KAPLAN, E. Ann. A mulher e o cinema - os dois lados da câmera. Rio de Janeiro: Editora Rocco, 1995.

KLEINER, Diana. Cleopatra \& Rome. Cambrigde and London: The Belknap Press of Harvard University Press, 2005.

SCHMITT, Jean-Claude. A história dos marginais. In: LE GOFF, Jacques. A História Nova. Tradução de Eduardo Brandão. São Paulo: Martins Fontes, 2001.

SCHWENTZEL, Cristian Georges. Cleópatra. São Paulo. L\&PM Pocket, 2009.

TONETTO, Maria Cristina (org). O olhar feminino no cinema. Santa Maria, RS: Centro Universitário Franciscano, 2011.

VADICO, Luiz. Cristologia fílmica: subsídios teórico-metodológicos para a análise da produção de imagens cristológicas geradas no cinema e na TV. Revista Estudos de Religião, Ano XXII, n. 34, p. 126-144, jan/jul. 2008.

WYKE, Maria. Projecting the past - Ancient Rome and History. Routledge, Londres, 1997. 